\title{
Erratum to: Knee stability after anterior cruciate ligament reconstruction in patients older than forty years: comparison between different age groups
}

Fabio Conteduca - Ludovico Caperna - Andrea Ferretti •

Raffaele Iorio • Carolina Civitenga • Antonio Ponzo

Published online: 20 November 2013

(C) Springer-Verlag Berlin Heidelberg 2013

Erratum to: International Orthopaedics (SICOT) (2013) 37:2265-2269

DOI 10.1007/s00264-013-2050-y

In the original publication of this paper, the names of the authors have been incorrectly presented.

We have updated the names in this Erratum paper.

The online version of the original article can be found at http://dx.doi.org/ 10.1007/s00264-013-2050-y.

F. Conteduca $\cdot$ A. Ferretti $\cdot$ R. Iorio $\cdot$ C. Civitenga

Azienda Ospedaliera S.Andrea, Via di Grottarossa,

1035-1039 Rome, Italy

L. Caperna $(\bowtie)$

Azienda Ospedaliera S.Andrea, Largo Olgiata 15 is. $70 \mathrm{~g} 1$, Rome,

Italy

e-mail: Kapezz@hotmail.com

A. Ponzo

Azienda Ospedaliera S.Andrea, Via F.A. Gualterio 70, Rome, Italy 